\title{
The study of the level of financial literacy of students of transport universities
}

\author{
Yana Nikonova ${ }^{1, *}$, Tatiana Lunina ${ }^{1}$, Aleksey Prudnikov $^{1}$, Ludmila Arshba ${ }^{1}$ \\ ${ }^{1}$ Siberian Transport University, Dusi Kovalchuk st., 191, 630049, Novosibirsk, Russia
}

\begin{abstract}
The purpose of this study is to characterize the state of financial literacy of students of transport universities on the basis of analysis of the results of empirical data of social research. In the framework of applied research, a significant amount of experience in assessing financial literacy has been gained, but in the academic science, the research of this kind is not enough to form a generally accepted concept and a detailed theory. Because of the resulting contradiction, the authors had to search for new approaches to conducting the study of financial literacy and interpreting the results. The system, in particular - the structural and functional approach and the sociocultural approach were chosen as the main ones. These approaches are widely used for study of similar phenomena and already proved themselves in science. As a result of the comparative analysis of the all-Russian level of knowledge and skills in the field of financial literacy and the level of students in the economic and noneconomic fields of study in transport universities, the hypothesis was proved that students of non-economic fields of study have a lower level of financial literacy compared to students in economic fields of study and allRussian level. Therefore, it is required to develop programs of various content and complexity to increase the level of financial literacy for these groups.
\end{abstract}

\section{Introduction}

In the current conditions of expanding the use of financial services, complicating, and the emergence of new and difficult to understand financial instruments, the issues of financial literacy of the population have become extremely relevant for most countries of the world. Ensuring personal financial security is becoming an important factor in the economic well-being of people.

In many countries around the world, awareness of the need to increase the financial literacy of the population has led to the formation of national strategies or financial education programs. Thus, an updated National Strategy for Financial Literacy [18] was adopted in the United States in 2016; the New Financial Capability Strategy for the UK [11] was published in the UK in 2015; the Financial Education Program [9] has been updated in Japan in 2015. It should be noted that for developed countries, this is not the first

\footnotetext{
*Corresponding author: ya_shka@ngs.ru
} 
strategy for improving financial literacy. The first strategy on financial literacy was developed in the USA - in 2006 [17], in the UK - in 2006 [12], in Japan - in 2005 [8].

One of the first major developing countries that began to work to increase financial literacy was India, which developed the National Strategy for Financial Education (NSFE) in 2012-2013 [15].

In the Russian Federation, the first Strategy for Improving Financial Literacy in the Russian Federation for 2017-2023 was approved at the end of 2017 [4].

Most of the studies in the field of financial literacy are sociopolitical studies commissioned by international economic organizations (World Bank [14], OECD [16]) or public organizations (the Financial Literacy and Education Commission in the USA (FLEC) [7], the Money Advice Service in England (MAS) [10], etc.). These studies are of an applied nature, and their main goal is to develop a national financial education strategy aimed at increasing the financial literacy of the population.

Assessment of the level of financial literacy of the population is a key element of a successful national financial education strategy that allows public authorities to identify gaps and develop appropriate solutions. International comparisons increase the value of such an assessment, allowing for cross-country comparisons. When similar patterns are identified in different countries, national authorities can work together to find common methods for increasing financial literacy in the relevant population groups.

The Russian Federation also conducts studies of the financial literacy of the population. In 2016, Russian citizens took part in an international comparative study of the level of financial literacy conducted by the Organization for Economic Cooperation and Development in 30 countries. According to the results of the study, Russia took the 25th place, gaining 12.2 points with an average assessment of financial literacy for all countries 13.2 points out of 21 possible [5].

In 2017, the Organization for Economic Cooperation and Development compiled a rating of financial literacy of the population of the G20 countries, in which Russia took the ninth place, gaining 12.2 points, while the average for the G20 was 12.7 points [3]. The latest OECD study showed that the financial knowledge and skills of the population of Russia remained practically unchanged.

In August 2016, the Analytical Center of the National Agency for Financial Studies conducted an all-Russian monitoring study, in which 1600 adult citizens took part. The data of the conducted surveys showed that the number of people who consider themselves financially literate has increased. The proportion of citizens with excellent/good knowledge and skills increased by $4 \%$ compared to 2015 and by $7 \%$ compared to 2008 , while the proportion of those who have unsatisfactory knowledge and skills does not have decreased from $34 \%$ (2015) to $25 \%$ (2016). Despite the increase in positive subjective assessment of their own level of financial literacy, citizens' skills still remain at a low level [6].

Also, a representative all-Russian survey of the National Agency for Financial Studies was conducted in May 2017. This year, no more than $12 \%$ of Russians polled by the Analytical Center of NAFI assessed their financial literacy as good or excellent. In 2016 this figure was $24 \%$. Thus, the results of numerous studies conducted in Russia indicate a low level of financial knowledge and skills of Russian citizens [1].

Such studies serve as the basis for creating a theoretical basis for the development of their own educational practices, the purpose of which is to teach the population to rationally manage their own financial resources and make effective financial decisions.

Most of the results of the studies conducted so far are presented in general for the entire population of Russia or its individual regions. However, when determining the level of financial literacy, we consider it necessary to identify group and type differences based on classification of the population. This will allow, first, to get a more objective assessment, 
and secondly, to develop targeted programs to increase the financial literacy of certain population groups in Russia.

Currently, most of the results of the studies are presented in general by the array (i.e. by the population of the Russian Federation, the population of its individual regions), and, taking into account the size of the country and individual regions, it is hardly possible to speak of an objective result.

When determining the level of financial literacy, it is important to classify the population in order to identify group and type differences. This will allow not only giving an objective assessment, but also subsequently to ensure targeting of programs to increase the financial literacy of the population.

The purpose of this study is to characterize the state of financial literacy of students of transport universities on the basis of analysis of the results of empirical data of social research.

At the same time, the main hypothesis of the study is the assumption that the basic level of financial literacy of students in economic and non-economic specialties varies considerably. Therefore, it is required to develop programs of various content and complexity to increase the level of financial literacy for these population groups.

\section{Materials and methods}

In the framework of applied research, a significant amount of experience in assessing financial literacy has been gained, but in the academic science, the research of this kind is not enough to form a generally accepted concept and a detailed theory. The absence of a common ideology of scientific search does not allow reliably interpreting the results of applied research in the field of financial literacy. The resulting contradiction required the authors to search for new approaches to conducting a study of financial literacy and interpreting the results. The system, in particular - the structural and functional approach, and the sociocultural approach approaches were chosen as the main ones. These approaches are widely used for research of similar phenomena and already proved themselves in science.

Representatives of the structural and functional approach consider society as a system of interconnected structures that form a single whole. As a part of this direction, research is being conducted on the contribution of different parts of society to the integration of the social system using the concept of "functional dependence".

The study of problems of financial literacy of the population with the application of the structural and functional approach presupposes a joint consideration of the structure and functioning of the elements of financial literacy with the subsequent construction of its model.

This study is based on the conceptual model of financial literacy by Angela A. Hung, Andrew M. Parker, Joanne Yoong [13] formed using the structural and functional approach. On the basis of this model, authors identified the following elements of financial literacy: financial knowledge, financial skills, and financial behavior.

The analysis of the selected elements of financial literacy should be carried out taking into account the parameters of the culture in which they are formed. The thesis that the behavioral attitudes of a person are determined and fixed in culture underlies the sociocultural approach, the basis of methodology of which is composed of the works of M. Weber, P. Sorokin, A. Akhiezer, N. I. Lapin, and others. Therefore, the sociocultural approach is used in this study to disclose the specifics of the sociocultural dynamics of financial literacy.

Empirical data used as evidence base was obtained by the authors during the following studies: 
1) the study "Attitude to money" carried out by the authors. Method of collecting information - questionnaire. In total, 200 students of transport universities at the age of 1819 years were interviewed, the period - November - December 2017. The study was of a probing nature, the problem of representativeness of the sample was not posed. Behavioral attitudes toward money were measured using value judgments. At the heart of the study is a test that allows determining the ability of a person to handle money.

2) the study "Financial literacy" carried out by the authors. Method of collecting information - questionnaire. In total, 200 students of transport universities at the age of 1819 years were interviewed, the period - January-February 2018. The study was of a probing nature, the problem of representativeness of the sample was not posed. Behavioral attitudes toward money were measured using value judgments. At the heart of the study is a test that allows determining the ability of a person to handle money.

\section{Results}

To study the level of financial literacy, the methodology was used to correlate the selfassessment of financial literacy of respondents with their financial attitudes and practices. Subjective assessment of respondents was revealed during the answer to the question: "Do you consider yourself a financially literate person? Do you have the necessary knowledge and skills in this field or do not have such knowledge and skills?".

As the basic financial practices and orientations, the following were selected: the practice of recording income and expenditure (question F2); daily practice of disposing of income (question F3); the practice of financial planning and its horizon (question F4); attitude to savings (question F5); attitude to credit (issue F6); attitude to money [2] (questions G1, G2, G17); the practice of making decisions on financial matters in the family (questions G3, G4); number of sources of income in the family (question G5); debt practices (G7-G13); attitude to the discussion of income level (questions G14-G15); practices and orientations for solving personal problems using the money (questions G16).

In the study, the proposed typology is based on self-assessment of the level of financial literacy of the respondents, and the following groups are identified:

1) financially illiterate, i.e. those who deny the availability of knowledge and skills in finance;

2) financially literate, i.e. those who indicated the availability of financial knowledge and skills, but because of the difference in the options for the answers were allocated:

- "outsiders" ("lagging behind") - unsatisfactory knowledge and skills;

- "conformists" ("mastering") - satisfactory knowledge and skills;

- "experts" ("making progress") - good knowledge and skills;

- "leaders" ("medalists") - excellent knowledge and skills.

The respondents who denied the availability of any knowledge and skills in the financial sphere were classified as financially illiterate. For them, the sphere of finance is unfamiliar, incomprehensible and causes rejection. The rest, with a certain degree of conventionality, can be attributed to financially literate, but it should be borne in mind that the degree of adaptation varies greatly among them.

It should be noted that the name of the groups is conditional and does not reflect the inherent hierarchy, i.e. a goal was set: to identify what financial knowledge, skills, attitudes, and orientations affect the formation of a self-assessment of financial literacy.

More than a third of the respondents are "conformists" who possess satisfactory knowledge and skills (38\%). "Experts" with good knowledge and skills accounted for 26\%, "outsiders" - 10\%. The smallest groups - "financially illiterate" and "leaders" - 4\% each. Due to the small number of these groups, the data obtained from them can only be used as reference that requires further study. It should be noted that almost a fifth of respondents 
(18\%) could not assess their knowledge and skills, and all of them are included in the group of respondents - students of non-economic specialties (Table 1).

To assess the differentiation of the level of financial literacy among university students, two arrays were identified: an array of "students of non-economic fields of study" and an array of "students of economic fields of study".

Table 1. The name and volume of the selected groups according to the author's typology.

\begin{tabular}{|c|c|c|c|c|c|c|}
\hline $\begin{array}{c}\text { Adaptability to } \\
\text { financial environment }\end{array}$ & $\begin{array}{c}\text { Financially } \\
\text { illiterate }\end{array}$ & \multicolumn{4}{|c|}{ Financially literate } & \\
\hline $\begin{array}{l}\text { Self-assessment of } \\
\text { financial literacy }\end{array}$ & 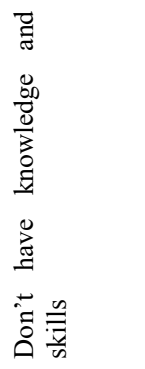 & 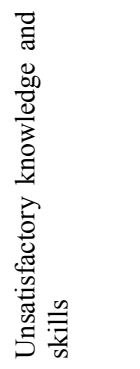 & 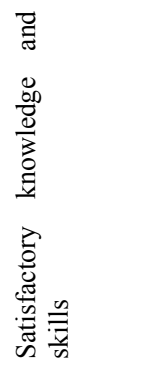 & 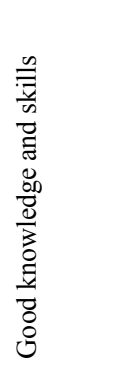 & 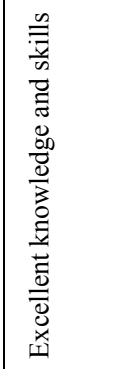 & $\begin{array}{l}\text { Couldn't } \\
\text { assess }\end{array}$ \\
\hline $\begin{array}{c}\text { The name of the } \\
\text { selected group when } \\
\text { using a typology } \\
\text { developed on the } \\
\text { basis of one factor }\end{array}$ & $\begin{array}{l}\text { "financially } \\
\text { illiterate" }\end{array}$ & "outsiders" & $\begin{array}{l}\text { "conformist } \\
\text { s" }\end{array}$ & "experts" & "leaders" & "undecided \\
\hline $\begin{array}{l}\text { Proportion of the } \\
\text { group in the general } \\
\text { array, } \%\end{array}$ & 4 & 10 & 38 & 26 & 4 & 18 \\
\hline $\begin{array}{l}\text { Proportion of the } \\
\text { group in the array of } \\
\text { "students of non- } \\
\text { economic fields of } \\
\text { study", \% }\end{array}$ & 8 & 16 & 28 & 12 & 0 & 36 \\
\hline $\begin{array}{l}\text { Proportion of the } \\
\text { group in the array of } \\
\text { "students of economic } \\
\text { fields of study", \% }\end{array}$ & 0 & 4 & 48 & 40 & 8 & 0 \\
\hline
\end{tabular}

The obtained results showed that in the array of "students of economic fields of study", "experts" make up a significant proportion - 40\% of the number of respondents in this array, and "conformists" - $48 \%$ of the number of respondents in this array. It was among students of economic fields of study that respondents were noted with excellent knowledge and skills - "leaders" - $8 \%$ of the number of respondents in this array. The proportion of "outsiders" in this array was only $4 \%$ of the number of respondents in this array. There were no financial illiterates.

In the array of "students of non-economic fields of study", a significant proportion of the respondents were "conformists" - $28 \%$ of the number of respondents in this array, and "outsiders" - $16 \%$ of the number of respondents in this array. The proportion of "experts" was $12 \%$ of the number of respondents in this array. It was among students of noneconomic fields of study that respondents were noted with a lack of financial knowledge and skills - "financially illiterate" - 4\% of the number of respondents in this array. There were no "leaders" (Fig. 1). 


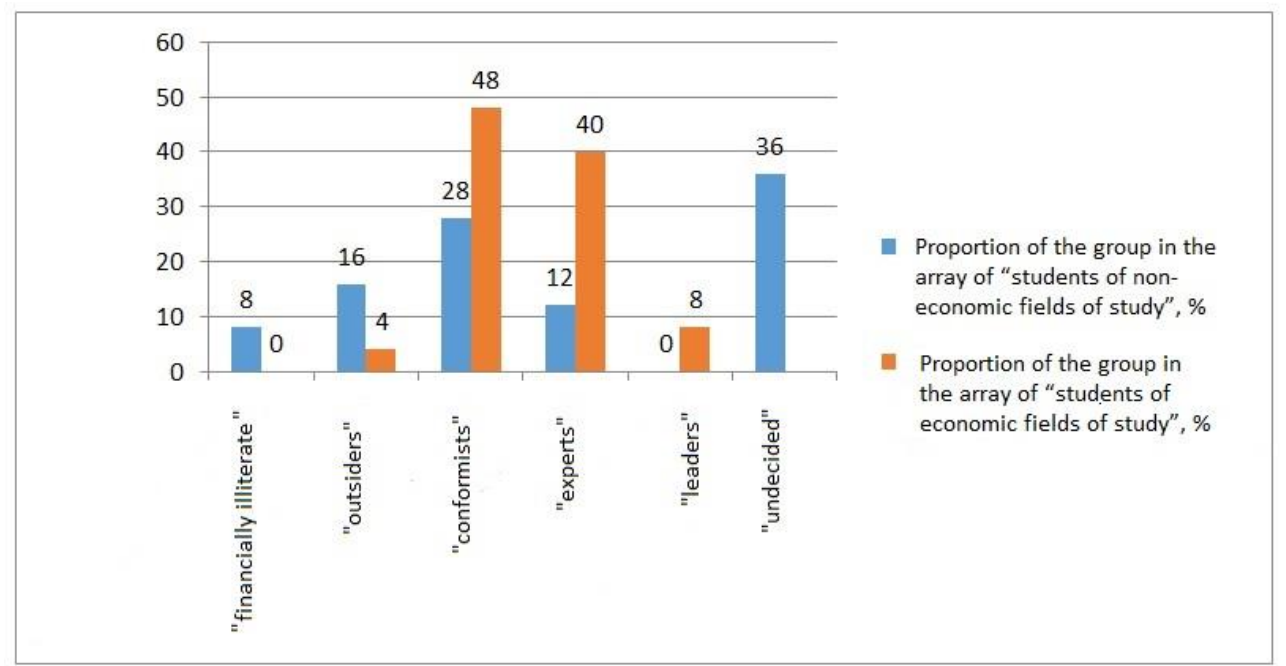

Fig. 1. Proportion of the allocated groups by level of financial literacy.

There is no rigid fixation in the allocated groups, under favorable or unfavorable conditions a person can move from one group to another, and an increase in the level of financial literacy can be judged by structural changes (an increase in the proportion of "leaders", "experts").

Thus, the conducted research confirmed the hypothesis that students of different fields of study have different levels of financial literacy. This circumstance must be taken into account when developing programs to improve financial literacy in universities.

\section{Discussions}

As a result of the study, it is shown that the level of financial literacy of students differs depending on the groups identified: the array of "students of non-economic fields of study" and the array of "students of economic fields of study".

In order to reveal the peculiarities of financial literacy of students, for example, the Siberian State Transport University (SSTU), the obtained results and all-Russian data were analyzed. The source of the all-Russian data was the results of the All-Russian survey of the NAFI "Financial literacy of the population: points of growth" conducted in August 2016 in 140 settlements in 42 regions of Russia $(\mathrm{N}=1600)$. The age of respondents is 18 years and older [6]. Comparison is made on questions with similar wording.

Table 2. Self-assessment of financial literacy of the population: comparison of all-Russian and author's data.

\begin{tabular}{|l|l|l|}
\hline Possible answers & $\begin{array}{l}\text { Results of the All- } \\
\text { Russian survey, 2016 }\end{array}$ & $\begin{array}{l}\text { Results of the survey of } \\
\text { the SSTU students, 2018 }\end{array}$ \\
\hline Excellent/good knowledge and skills & 24 & 30 \\
\hline Satisfactory knowledge and skills & 51 & 38 \\
\hline Unsatisfactory/no knowledge and skills & 25 & 14 \\
\hline Could not assess & 0 & 18 \\
\hline
\end{tabular}

The ratio of groups nearly coincides (within the limits of statistical error), the excess of the proportion of "outsiders" and "financially illiterate" in Russia by 1.8 times is significant. This excess was obtained, most likely, due to the proportion of "undecided" respondents who could not assess their level of financial literacy. In general, the average 
value of self-assessment of the financial literacy of the SSTU students is slightly higher than in Russia at all.

Figure 2 presents a comparison of the distribution of the level of self-assessment of the financial literacy of the population of the Russian Federation as a whole and students of the SSTU, including the selected arrays.

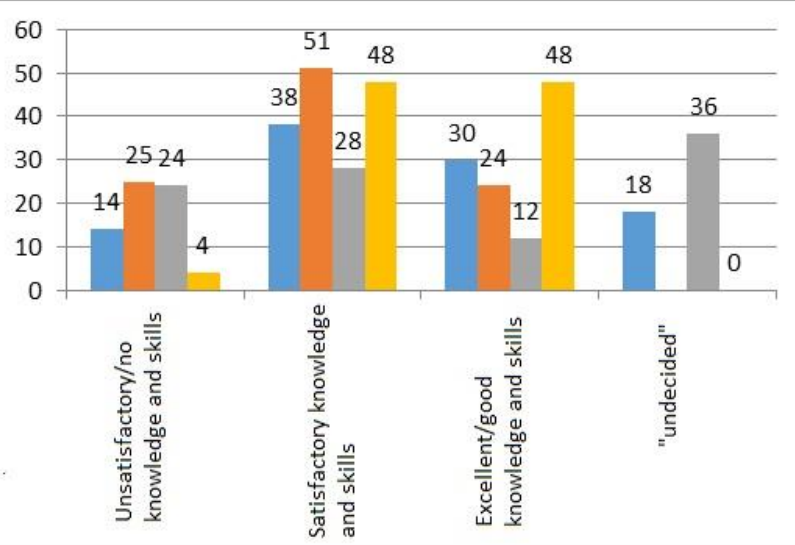

\footnotetext{
- Results of the survey of the SSTU students, 2018

Results of the AllRussian survey, 2016

Proportion of the group in the array of "students of noneconomic fields of study", \%

Proportion of the group in the array of "students of economic fields of study", $\%$
}

Fig. 2. Comparative analysis of all-Russian and author's results of self-assessment of financial literacy of the population.

As the most important results of the study, it should be noted that the proportion of respondents whose knowledge and skills in the field of financial literacy is unsatisfactory or absent among students of the economic fields of study is 6 times lower than that of students of non-economic fields of study and all-Russian levels. Another significant result is that the proportion of respondents who have excellent or good knowledge and skills among students in economic fields of study is 2 times higher than the all-Russian level, and 4 times (!) higher than among students in non-economic fields of study.

Thus, as a result of the comparative analysis of the all-Russian level of knowledge and skills in the field of financial literacy and the level of students of economic and noneconomic fields of study in transport universities, it once again confirmed the hypothesis that students of non-economic fields of study have a lower level of financial literacy than students of economic fields of study and the all-Russian level.

Therefore, it is required to develop programs of various in content and complexity to increase the level of financial literacy for students of economic and non-economic fields of study.

\section{References}

1. $12 \%$ of Russian surveyed by NAFI estimated their financial literacy as good, http://www.kommersant.ru/doc/3384234

2. O.S. Deineka, Psychological Journal 3-2, 36-46 (2002)

3. OECD (2016), G20/OECD IFRS, The concept of basic knowledge and skills in financial literacy for the adult population, https://fingramota.econ. msu.ru/sys/raw.php?o=1519\&p=attachment

4. Government Resolution of the Russian Federation of September 25, 2017 №2039-r On the approval of the Strategy for improving financial literacy in the Russian Federation for 2017-2023, http://www.garant.ru/products/ipo/prime/doc/71675558/\#ixzz 5CQHU9Hzn 
5. Russia ranks 25th in terms of financial literacy in the world, Overview of NAFI (Moscow, 2016)

6. Financial literacy of the population: points of growth. Overview of NAFI (Moscow, 2016)

7. 2016 Financial Literacy Annual Report, Consumer Financial Protection Bureau, https://www.consumerfinance.gov/data-research/research-reports/2016-financialliteracy-annual-report/

8. Agenda for Finance and Economics Education (JFSA, 2005)

9. CCFSI Financial Education Program, https://www.shiruporuto.jp/e/consumer/pdf/financial_education_goals_by_age_group. pdf

10. Financial Capability of Children, Young People and their Parents in the UK 2016. Initial results from the 2016 UK Children and Young People's Financial Capability Survey (2017)

11. Financial Capability Strategy for the UK, https://www.fincap.org.uk/uk_strategy

12. Financial Capability in the UK: Delivering Change, http://www.fsa.gov.uk/pubs/other/fincap_delivering.pdf

13. A.A. Hung, A.M. Parker, J. Yoong, Defining and Measuring Financial Literacy (RAND Corporation, 2009)

14. T. Kaiser, L. Menkhoff, Policy Research Working Paper 8161 (2017) https://openknowledge.worldbank.org/handle/10986/27968

15. National Strategies for Financial Education: OECD/INFE Policy Handbook (OECD Publishing, 2015)

16. OECD/INFE International Survey of Adult Financial Literacy Competencies (OECD Publishing, 2016)

17. Taking Ownership of the Future: The National Strategy for Financial Literacy (2006 National Strategy), https:/www.treasury.gov/about/organizationalstructure/offices/Domestic-Finance/Documents/Strategyeng.pdf

18. The National Strategy for Financial Literacy 2016, https://www.treasury.gov/resourcecenter/financial-education/Documents/National\%20Strategy\%20for\%20Financial $\% 20$ Literacy\%202016\%20Update.pdf 